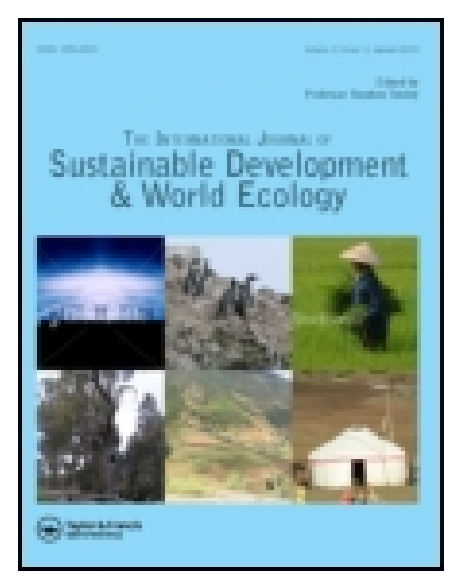

International J ournal of Sustainable Development \& World Ecology

Publication details, including instructions for authors and subscription information: http:// www. tandfonline.com/loi/tsdw20

\title{
Impact of tourism development on land-cover change in a matriarchal community in
} the Lugu Lake area

Rencai Dong, Lijun Yu \& Guohua Liu

Published online: 20 Sep 2010.

To cite this article: Rencai Dong , Lij un Yu \& Guohua Liu (2008) Impact of tourism development on land-cover change in a matriarchal community in the Lugu Lake area, International J ournal of Sustainable Development \& World Ecology, 15:1, 28-35, DOI: 10.1080/ 13504500809469765

To link to this article: http:// dx.doi.org/ 10.1080/13504500809469765

\section{PLEASE SCROLL DOWN FOR ARTICLE}

Taylor \& Francis makes every effort to ensure the accuracy of all the information (the "Content") contained in the publications on our platform. However, Taylor \& Francis, our agents, and our licensors make no representations or warranties whatsoever as to the accuracy, completeness, or suitability for any

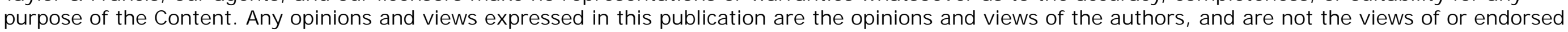

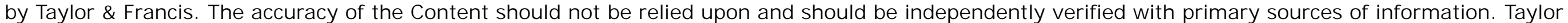

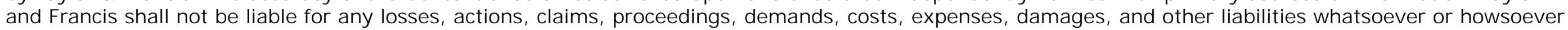
caused arising directly or indirectly in connection with, in relation to or arising out of the use of the Content.

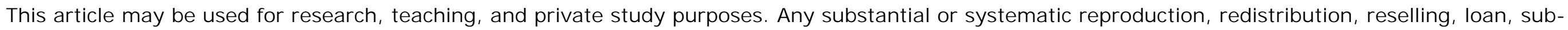
licensing, systematic supply, or distribution in any form to anyone is expressly forbidden. Terms \& Conditions of access and use can be found at http:// www.tandfonline.com/page/terms-and-conditions 


\title{
Impact of tourism development on land-cover change in a matriarchal community in the Lugu Lake area
}

\author{
Rencai Dong, Lijun Yu and Guohua Liu
}

State Key Laboratory of Urban and Regional Ecology, Research Center for Eco-Environmental Sciences, Chinese Academy of Sciences, Beijing, China

Key words: Land-cover change; Lugu Lake; Mosuo people; tourism development; ecosystem management

\begin{abstract}
SUMMARY
Remote sensing was used to assess the impacts of tourism development on temporal land-cover changes in the Lugu Lake region, home to the Mosuo people. The ecological and economic significance of the Lugu Lake area derives from the existence of a unique matriarchal system and the success of tourism development. Temporal land-cover changes between 1990 and 2005 were evaluated using digital interpretation of multitemporal Landsat TM images. Pairwise comparison methods were used to quantify changes in land-cover during three periods: 1990 to 1995, 1995 to 2001, and 2001 to 2005. The areas surveyed in each period were 10,226 ha, 7,727 ha and 9,344 ha, respectively. The annual rate of land-cover change for farmland, forest, grassland and wetland were $2.86 \%, 5.85 \%, 3.95 \%, 6.28 \%$, respectively. Farmland and wetland have decreased, whereas forest, grassland and residential areas have increased. The land-cover changes could be explained by the success of tourism development and ecosystem management in Lugu Lake region. The impact of tourism on land cover and the community environment were assessed. The results show that most farmers actively left farms for off-farm jobs and took measures to protect forest, grassland and wetland by developing tourism in the study area. However, construction in residential areas has proceeded in a disorderly fashion. In future, the potential impacts of tourism on the lake ecosystem need to be re-assessed and monitored.
\end{abstract}

\section{INTRODUCTION}

The most important direct driver of changes in ecosystem services over the past 50 years has been land-cover change (Millennium Ecosystem Assessment 2005). Transformed land cover is one of the main manifestations of human influence on the environment. Hence, analysis of land-cover change is a salient topic in ecosystem research. Estimates of temporal land-cover change enable assessment of the rate at which changes advance and to connect them with problems or impacts, hence allowing improved prediction of future impacts and trends (Lambin 1997).

A region's land cover is a constantly changing mosaic of cover types determined by both the

Correspondence: Guohua Liu, State Key Laboratory of Urban and Regional Ecology, Research Center for Eco-Environmental Sciences, Chinese Academy of Sciences,18 Shuangqing Road, Haidian District, Beijing 100085, China. E-mail: ghliu@rcees.ac.cn 
physical environment and human activities (Skole 1996). Historically, the most important land-use changes imposed by man were the clearing of forests for agriculture or human settlement. Subsequent technical developments in the 19th and 20th centuries, together with the growing human population, have increased man's ability and need to shape the environment according to his requirements (Lausch and Herzog 2002). In China, because of poor accessibility until the late 1970s, many communities in mountainous areas were still living in a relatively closed environment with poor economic conditions. This helped to preserve the pristine natural environments and unique cultures. Due to rich natural and cultural resources, tourism developed very rapidly in Yunnan Province afte the implementation of China's economic reforms in 1978, and especially in the wake of China's recen policies aimed at hastening development in the western part of the country. Tourism, in particular, was a logical strategy for development in this area, given the abundance of untouched natural areas, and has become a major economic resource for many of China's nature reserves over the past 10 years (Li 2004).

In Yunnan Province, many villages with ethnic communities have been promoted as tourist attractions. Showcasing natural beauty and resources, cultural heritage and traditional customs has been the focus of efforts to achieve maximum tourism income and to alleviate local poverty. Tourism has greatly promoted economic growth. The opportunities for exploitation of resources for development are diverse. Tourism development differs from agriculture with respect to resource use and environmental impact. Therefore, tourism development in ethnic communities mainly involves human modifications to ecosystems and land cover. Nowadays, both the public and policy-makers have paid close attention to human-induced ecosystem changes a ourism sites, because the ecosystem provides environmental goods and services not only for the local people but, more importantly, for regional sustainable development. Social and economic considerations are among the most important drivers of land-cover changes, yet few studies have addressed tourism's influence on land-cover change trends Land-cover changes are also a political and economic issue. Some of the measures designed to protect tourism resources have had a positive impact on local people in China.
Our objective was to demonstrate a methodology that relies on multi-temporal remote sensing satellite data and digital image interpretation techniques to monitor land-cover change in Lugu Lake region. The spatial and temporal dynamics of land cover in Lugu Lake region from 1990 to 2005 were analysed. By integrating socio-economic and spatial information collected from household and tourist interviews, land-use mapping and policy review, the research results show that a tourism-oriented nature conservation strategy has made a positive contribution in Lugu Lake region.

\section{MATERIALS AND METHODS}

\section{Study area}

The study area is located in northern Lijiang Prefecture, on the border between Sichuan and Yunnan Provinces (see Introduction for further detail), covering an area of 50,956.6 ha. Influenced by regional geology and active tectonic plate movement from a collision of the Indian subcontinent with the Eurasian continent, the landform is quite fragile, complex and diverse. The climate in the foothills is subtropical, becoming temperate in the mountain areas. The main soil type is red soil. The Lugu Lake watershed is mainly limestone, mud stone and sandstone.

The Mosuo, a branch of the Naxi ethnic group, live around Lugu Lake. Mosuo mainly live in northeastern Lijiang Prefecture and along the banks of the Jinsha River, and have a total population of about 40,000. They follow a matriarchal system, in which most individuals spend their whole lives in the maternal family home and never marry their partners. Lugu Lake region contains a large number of Mosuo who settled in this area more than 1,500 years ago, and assimilated Tibetan, Mongolian, Yi, Naxi and Pumi cultures to form their own unique Mosuo culture. The total population of the study area was 30,000 with a population density of $58 \mathrm{~km}^{-1}$ in 2005 .

With its beautiful natural scenery, flourishing forests and clear lake, the study area has rich natural and cultural tourism resources. Up to the 1980s, although agricultural technology had advanced greatly and agricultural productivity had been much improved, agricultural production in the region still lagged behind areas employing more conventional techniques. Because of its 
mountainous and remote location, the local people in the lake region lived in a relatively closed environment with a very low standard of living. The cultural features of the ethnic groups were, therefore, well preserved.

Recently, the local villagers have gained great economic returns from developing tourism. Major changes have taken place since tourism development began in the late 1980s. As the villages have become more and more tourism-oriented, thei economy has transferred from relying on agriculture to tourism; the living environment has changed from closed to open; and the way of life has evolved from traditional matrilineal marriages and families to assimilation into modern life. The area has now become a renowned ethnic tourist destination, for both Chinese and foreign tourists. The Lugu Lake experience has important implications for research, education and conservation.

A background area was designated in order to contrast land-cover change with the study area. The background area surrounding Lugu Lake, covered 880,288 ha and was populated mainly by non-Mosuo people and characterised by a lack of tourism.

\section{Data}

Remote sensing techniques have proved very useful for providing reliable information on land-cover change. Two types of data are used in this study: satellite image data and ground reference data Satellite image data were obtained from four Landsat TM images (path: 131, row: 41) acquired in 1990, 1995, 2001 and 2005. In order to avoid the effects of seasonal changes on the Earth's surface, the Landsat TM data for the same season (winter) were used (Table 1). Ground reference data consisted of topographic maps and a land-use map printed in 1996, provided by the Ministry of
Defence General Command of Mapping, as source reference information for classifying satellite images and validating change information. Present landcover information was collected on the ground by GPS measurements in 2005, nearly simultaneously with image acquisition.

\section{Methods}

Land-cover change analysis is comprised of three main steps: classifying satellite images, extracting land-cover information, and generating a change matrix (Fig. 1)

\section{Pre-processing satellite images}

All image processing was carried out with the program ERDAS 8.7. Geometric correction of images was implemented by referencing topographic maps, achieving a root mean square deviation of less than 0.5 pixels. The coordinates were based on the Gauss Kruger projection, Krassovsky sphere.

Land-cover classification system

The first step in performing image classification was to select a land-cover classification system (Currit 2005). By considering vegetation type, a soil map and other features, the land-cover classification

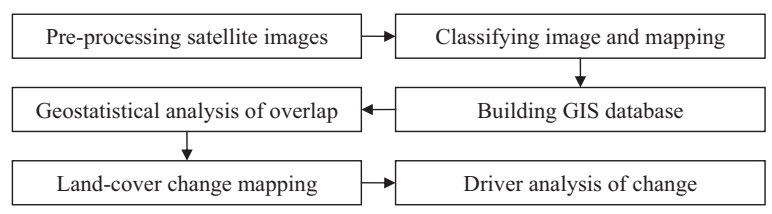

Figure 1 Flow diagrams of the land-cover change analysis

Table 1 Metadata of satellite images and ground reference data

\begin{tabular}{llcc}
\hline Data type & \multicolumn{1}{c}{ Resource } & Resolution/Scale & Acquired \\
\hline Satellite images & Landsat-5 TM & $30 \mathrm{~m}$ & $13 / 1 / 1990$ \\
Satellite images & Landsat-5 TM & $30 \mathrm{~m}$ & $11 / 1 / 1995$ \\
Satellite images & Landsat-5 TM & $30 \mathrm{~m}$ & $19 / 1 / 2001$ \\
Satellite images & Landsat-5 TM & $30 \mathrm{~m}$ & $6 / 1 / 2005$ \\
Topographic maps & Ministry of Defence General Command of Mapping & $1: 50000$ & 1966 \\
Land-use maps & Ninglang County Land Bureau & $1: 25000$ & 1994 \\
Forest maps & Forest Inventory and Planning Institute of Yunnan Province & $1: 50000$ & 1986 \\
GPS point sets & Collected by ourselves & $10 \mathrm{~m}$ & 2005 \\
\hline
\end{tabular}


system for the Lugu Lake study area was built from five level 1 and 19 level 2 classifications (Table 2).

Classification

Image classification began by defining training regions for a classification algorithm and extracting simple descriptive statistics for the training pixels selected. The training statistics are then presented to the classification algorithm that defines a set of discrimination functions that separate unique spectral regions into land-cover classes. Land-cover classification was carried out using the supervised maximum likelihood algorithm in terms of level 2 Then, all classified images were recoded into level 1 , according to the groupings presented in Table 2 After recoding, classified image attributes contained only five land-cover classes: farmland, forest grassland, wetland and residential area.

\section{Accuracy assessment}

In order to validate the final classification results, the checkpoint system was used to verify the data. The checkpoints were generated from land-use maps and ground investigation data. Land-use maps printed in 2000 by the Ninglang County Land Bureau have been digitised. In addition, using GPS 150 monitoring points were collected and used to generate the validation map. The conventional method of assessing accuracy was used (Congalton 1991; Niel and McVicar 2004). Table 3 shows the accuracy of all output maps.

\section{Raster to vector and GIS database}

With the Vector Model from the program ERDAS 8.7 (ERDAS Inc. 1995), the final classified images were converted from raster to vector format for building the GIS database. The information on land cover was converted from the RS to the GIS platform. For convenience of analysis, the Geodatabase data model was introduced. The Geodatabase data model is a modern GIS data model that evolved from many years of research and was developed by the Environmental Systems Research Institute (ESRI). Using the Geodatabase format, the data can be stored and processed by the Relationship Database Management System (RDBMS). In this study, Microsoft Office Access was adopted for
Table 2 Land-cover classification system for the study area

\begin{tabular}{ll}
\hline Level 1 & Level 2 \\
\hline Farmland & Irrigable land \\
& Non-irrigable land \\
& Fallow \\
Forest & Mixed fir and spruce \\
& Spruce \\
& Yunnan pine, young \\
& Yunnan pine, older \\
& Broadleaf \\
& Shrubs \\
& Orchards \\
Grassland & Upland grassland \\
Wetland & Swamp \\
& Stream \\
& Lake \\
& Reservoir \\
Residential area & Houses \\
& Residential hotels \\
& Roads \\
& Mining areas \\
&
\end{tabular}

Table 3 Accuracy assessment of multitemporal landcover classification

\begin{tabular}{lcccc}
\hline Item & 1990 & 1995 & 2001 & 2005 \\
\hline Overall accuracy & 76.6 & 78.3 & 74.6 & 80.2 \\
Average class accuracy & 77.2 & 79.6 & 74.8 & 81.6 \\
Kappa coefficient & 0.68 & 0.70 & 0.66 & 0.72 \\
\hline
\end{tabular}

managing land-cover information collected for Lugu Lake region.

\section{Overlay analysis and change detection}

In order to work with more than one data layer that describes the same region on the same projection and scale, the layers are superimposed on each other, thereby creating new spatial figures or new properties. Using the ArcGIS platform, Overlay analysis was used to combine the two layers (prechange and post-change layer) and the result was used to form a new layer, which inherited the object attributes and characteristics of the original layers. Through the new layers, the detection information can be acquired from the following procedure. If the land-cover attributes of a pre-change patch did not equal the land-cover attributes of a post-change 
patch, then that patch was changed. Hence, the change information of each pairwise comparison, including those from 1990 to 1995, 1995 to 2001 2001 to 2005, and 1990 to 2005 can be acquired. Using this information, the land-cover conversions matrix was generated.

\section{Rate of land-cover change}

Formula 1 was used to quantify the rate of landcover change (Xu et al. 2005).

$$
\mathrm{Rc}=\frac{C_{b}-C_{a}}{C_{a}} \times \frac{1}{T} \times 100 \%
$$

Where $R_{c}$ represents the annual rate of land-cove change, $C_{a}$ the amount of the particular land cover at the beginning of year ' $a$ ', $C_{b}$ the amount at the end of year ' $\mathrm{b}$ ', and $T$ represents the length of time.

\section{Socio-economic survey}

A socio-economic survey was carried out by collecting secondary data from government agencies on population, tourism, the area of cultivated field and food production. Statistical yearbooks from 1990 to 2004, compiled by the Bureau of Statistics of Ninglang County, were used directly. In 2005, data were collected by our research group from villages in the watershed. Moreover, many data were gathered by interviewing key informants about policy planning and implementation related to tourism as well as local people about historical events and land-cover change trends.

\section{RESULTS}

\section{Summary of land-cover changes}

Table 4 shows the area change of each land cove class in 1990, 1995, 2001 and 2005. In summary, three different phrases were presented for each type of land cover. Farmland and wetland experienced more loss, while forest and grassland showed significant increases in area. Residential area had developed heavily since the beginning of the 21st century.

From 1990 to 1995, farmland area increased from 7,709 ha to 8,971 ha, and $R_{c}$ was $0.495 \%$. From 1995 to 2001, $R_{c}$ decreased by $0.136 \%$. From 2001 to $2005, R_{c}$ decreased by $1.682 \%$. From 1990 to 1995 , forest decreased at an annual rate of $0.589 \%$, but between 1995 and 2005, it increased by $0.523 \%$
Table 4 Area changes of land-cover types in the Lugu Lake region (ha)

\begin{tabular}{lrrrr}
\hline Ecosystem type & 1990 & 1995 & 2001 & 2005 \\
\hline Farmland & 7709 & 8971 & 8682 & 5126 \\
Forest & 33261 & 31759 & 33321 & 35127 \\
Grassland & 2425 & 2421 & 2659 & 3742 \\
Wetland & 7293 & 7514 & 5994 & 6457 \\
Residential area & 269 & 292 & 301 & 505
\end{tabular}

each year, from 2001 to $2005, R_{c}$ was $0.867 \%$. The trend for grassland was similar to forest, decreasing at an annual rate of $0.002 \%$ between 1990 and 1995 and then increasing by $0.089 \%$. From 2001 to 2005 , it increased sharply at an annual rate of $0.515 \%$.

Compared to other natural ecosystems, wetlands showed a different trend. During the period from 1990 to 1995 , the wetland area increased from 7,293 ha to 7,514 ha, but decreased to 6,457 ha by 2005. The residential area has increased continuously since 1990, especially from 2001 to 2005, when growth accelerated to an annual rate of $0.094 \%$.

\section{Analysis of the land-cover change matrix}

Table 5 presents the land-cover change matrix of each land type from 1990 to 2005 . The $R_{c}$ of farmland, forest, grassland and wetland was $2.86 \%$, $5.85 \%, 3.95 \%$ and $6.28 \%$, respectively. The degree of land-cover change was ranked from smallest to largest as follows: farmland $>$ grassland $>$ forest $>$ wetland. Furthermore, about $95.2 \%$ of the new residential areas was constructed between 1990 and $2005\left(R_{c}=6.35 \%\right)$.

Although land-cover changes exhibited complex and multidirectional characteristics, the conversion that occurred between farmland and forest was dominant. About $14 \%$ of farmland was converted to forest, whereas about $5.3 \%$ of forest was converted to farmland from 1990 to 2005 . The net change reflects a conversion of $8.7 \%$ of farmland to forest. Similarly, about $6.2 \%$ of farmland became grassland and $14.2 \%$ of grassland was converted to farmland.

\section{Comparison between study area and background area}

Table 6 shows the area of land-cover changes from the background area. Here, farmland and wetland 
Table 5 Land cover conversion matrix from 1990 to 2005 (ha)

\begin{tabular}{rlrrrrr}
\hline \multicolumn{1}{c}{ Land cover } & Farmland & Forest & Grassland & Wetland & Residential area \\
\cline { 2 - 6 } & Farmland & 2167 & 388 & 171 & 17 & 26 \\
\multirow{2}{*}{1990} & 1861 & 32012 & 1111 & 204 & 48 \\
& Forest & 958 & 3718 & 1892 & 121 & 42 \\
& Grassland & 291 & 3 & 5548 & 4 \\
& Wetland & 15 & 13 & 0 & 6 \\
\hline
\end{tabular}

decreased, while forest, grassland and residential area increased. After detailed comparison with the study area, however, some different trends were identified. First, the amount of farmland and wetland in the background area decreased by $R_{r} 3.68 \%$ and $R_{c} 2.85 \%$, respectively, a difference larger than in the study area. In other words, the farmland and wetland in the study area were more stable compared to those in the background area. In the study area, grassland increased more than in the background area, while the $R_{c}$ of the residential area was $36.8 \%, 6.5$-times that observed in the study area $\left(R_{c}\right.$ $=5.68 \%)$. Therefore, changes in land cover in the study area were less drastic than those in the background area.

\section{DISCUSSION}

\section{Driving forces behind land-cover change}

The observed trends in land-cover change could potentially be explained in part by recent trends in economic growth, changes in the tourist population, and ecosystem management in the study area. From 1990 to 1995, there were few tourists in Lugu Lake region, and revenues from tourism were low. Agriculture was the dominant industry, and residents' livelihoods depended on farm labour and harvest productivity. Farmland was protected absolutely. The aboriginal Mosuo had continued to cu forest and burn grassland to create more farmland. Hence, during this period, farmland area increased and forest and grassland area decreased.

From 1995 to 2005, the tourist population in the area increased 2.5-fold. The increase in farm income mainly came from the development of tourism. On the banks of Lugu Lake, the commercially developed area was expanded, and the number of residential hotels in these areas also increased. Moreover, projects aimed at restoring farmland to
Table 6 Land-cover conversion in background area between 1990 and 2005 (ha)

\begin{tabular}{lrrrr}
\hline Land cover & 1990 & \multicolumn{1}{c}{1995} & \multicolumn{1}{c}{2001} & \multicolumn{1}{c}{2005} \\
\hline Farmland & 107220 & 74910 & 97740 & 48050 \\
Forest & 649970 & 687980 & 698540 & 715360 \\
Grassland & 48290 & 38390 & 53940 & 59520 \\
Wetland & 71850 & 76600 & 17000 & 41160 \\
Residential area & 1860 & 1300 & 9610 & 12140 \\
\hline
\end{tabular}

forest or grassland and imposing a logging ban were the main drivers for growth of forest and grassland. On October 1 1998, after the most extensive flooding ever in the Yangtze basin, the Chinese government implemented the state logging ban policy, known as the Natural Forest Protection Programme (NFPP). The ban on logging was immediately followed by the Sloping Land Conversion Programme (SLCP) policy in 1999 (Li 2004; Weyerhaeuser et al. 2006). This programme was designed to address the problem of cultivation on hill slopes, a major factor contributing to soil erosion and flooding. According to this policy, any farmland with a gradient of more than $25^{\circ}$ must be converted to forest or grassland. To facilitate the conversions, farmers receive tree seedlings and government subsidies for grain, education and healthcare. Combined with the effects of the logging ban, the volume of annual allowable forest cutting dropped to zero. Hence, new growth forest increased by 720 ha, regenerated forest by 11,850 ha and protected area, by sealing a mountain pass, by 18,457 ha between 1998 and 2000 From 2000 to 2005, the local people afforested 127 ha each year at an annual rate of $0.6 \%$. As a result, forest has significantly increased, with an annual rate of $2.2 \%$ of land-cover change.

Because local farmers had attempted to tame the Yongning River and had converted its natural channel into an artificial channel by building a 
concrete riverway, ponds and bottomlands around this river, the wetland area also decreased between 1990 and 1995. During the period from 2001 to 2005 , about $5 \%$ of the wetland was converted to forest because the Mosuo planted fruit trees in the wetland. This was disadvantageous for ecosystem functioning: first, the high water level $(0.6 \mathrm{~m})$ could limit the growth of trees; and second, the change from the original wetland ecosystem to an artificial forest ecosystem could reduce natural wetland ecosystem services, such as supporting certain mammals or storage of floodwater (for mitigation of floods).

\section{Relationship between tourism development and land-cover change}

Previous research had shown that Lugu Lake region had become more and more open to the outside (Xu et al. 2005), and that the village economy had shifted from relying on agriculture to reliance on tourism since the 1990s. Tourism development of Lugu Lake region could be divided into three stages as outlined below (Bureau of Statistics of Ninglang County 1990-2004)

Early stage (1988-1992): very few visitors. Most visitors belonged to official delegations of scholar and researchers. In 1989, total visitors to Lugu Lake tourist region were 6,120 . Because there were no facilities for tourist accommodation, tourists stayed in homes of the Mosuo. Hence, land-cover change was stable, especially in residential areas.

Development stage (1993-1999): in November 1992, Lugu Lake region was approved as a touris destination by the State Council and began to open to tourists. In 1994, the government of Yunnan Province made a policy to give priority to tourism development and decided to develop Lugu Lake region into a provincial level tourist destination. In 1997, the total number of visitors to Lugu Lake tourist region increased to 100,000 . At this stage, a type of natural and ethnic tourism was taking shape in the region. The typical accommodation for tourists was changed into two-storied Mosuo-style ethnic inns. In 1992, Lugu Lake was officially opened as a tourist destination. With continued improvement of roads and infrastructure and rapid growth of China's tourism, tourism in Lugu Lake region developed very fast. Tourism has provided a new way for people around the lake to tap into local resources to make a living. This has directly affected the life of the local people.

Mature stage (2000-2005): in 1999, Lugu Lake region was designated as one of 43 major tourist development projects in China. The LijiangNinglang highway opened to traffic in the same year. The road runs through the study area and has greatly promoted tourism growth in the villages. In 2003, the total number of tourists to Lugu Lake tourist region reached 400,000 . In order to meet the needs of the large numbers of tourists, villagers began to renovate their houses to accommodate tourists, and other facilities were improved accordingly. Consequently, the residential area increased along with the tourist population (Fig. 2). Currently, the accommodation capacity in some villages has reached over 3,000 beds. The more tourists that can be accommodated, the more the expected income gained. Almost every household has renovated their house into an ethnic inn to accommodate tourists. Some of the households have extended their traditional houses to add more guest rooms. The villagers have accepted tourism and are basically satisfied with the path of development at this stage.

Since the late 1990s, tourism has replaced agriculture and the raising of livestock, and has become the dominant occupation and source of income in Lugu Lake region. This can be seen from changes in economic structure in the villages in the last 15 years. In 1990, agriculture and livestock were the major income sources. For example, the annual average income per villager was 196 Yuan in 1988 and the annual grain ration, mainly maize and potatoes, was $190 \mathrm{~kg}$ per person. However, in 1994, tourism provided $49.2 \%$ of the villagers' total income, and in 1996 the percentage increased to $83.3 \%$. At

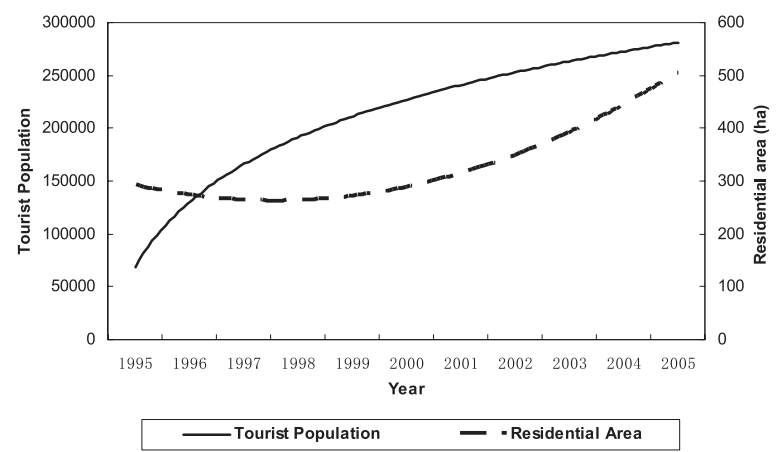

Figure 2 The curve of population and residential area in study area from 1995 to 2005 
present, the percentage has increased to $95.6 \%$. This research indicates that farmers have a stronger inclination to convert farmland to grassland. The former farmers actively left their farmland for off-farm jobs and now spend more time focusing on non-timber forest products, such as cultivating mushrooms, providing fresh water, rowing boats, leading horses and organising dance shows. Tourism development has also resolved the contradiction between development of farmland and forest.

\section{CONCLUSIONS}

This land-cover change analysis shows the success of both tourism development and natural conservation programmes in Lugu Lake region. With the development of tourism, forest and grassland have significantly increased, in parallel with a decrease in farmland, and natural ecosystems have been revived significantly since 1990 . The farmers have actively left their farmland for off-farm jobs and have participated in the protection of the landscape of forest, grassland and wetland as tourism has developed. However, the residential area around the banks of Lugu Lake was constructed in a disorderly fashion, and there have been reports of degraded water quality. Hence, in the future, the potential impacts of tourism on lakeland ecosystem quality need to be further assessed and monitored.

\section{ACKNOWLEDGEMENTS}

This study was supported by the Chinese Academy of Sciences (KZCX3-SW-438), the National Natural Science Foundation of China (No. 70325002), and the Ministry of Science and Technology of the People's Republic of China (2005DIB3J002).

\section{REFERENCES}

Bureau of Statistics of Ninglang County. Statistical year book series from 1990 to 2004. Ninglang: Bureau of Statistics of Ninglang County; 2004

Congalton RG. A review of assessing the accuracy of classifications of remotely sensed data. Remote Sensing of Environment 1991;37:35-46

Currit N. Development of a remotely sensed, historical land-cover change database for rural Chihuahua Mexico. International Journal of Applied Earth Observation and Geoinformation 2005;7:232-47

ERDAS Inc. ERDAS Imagine Field Guide. Atlanta GA 1995

Lambin E. Modelling and monitoring land-cover change processes in tropical regions. Progress in Physical Geography 1997;21:375-93

Lausch A and Herzog F. Applicability of landscape metrics for the monitoring of landscape change: issues of scale, resolution and interpretability. Ecological Indicators 2002;2:3-15

$\mathrm{Li}$ W. Environmental management indicators for ecotourism in China's nature reserves: A case study in Tianmushan Nature Reserve. Tourism Management 2004;25:559-64

Li WH. Degradation and restoration of forest ecosystems in China. Forest Ecology and Management 2004;201:33-41

Millennium Ecosystem Assessment. Ecosystems and Human Well-being: Synthesis. Washington DC: Island Press; 2005

Niel TGV and McVicar TR. Current and potential uses of optical remote sensing in rice-based irrigation systems: a review. Australian Journal of Agricultural Research 2004;55:155-85

Skole D. Land Use and Land Cover Change (LUCC). The Earth Observer, reprint from Global Change Newsletter No. 25; 1996

Weyerhaeuser H, Wilkes A and Kahrl F. Local impacts and responses to regional forest conservation and rehabilitation programs in China's northwest Yunnan province. Agricultural Systems 2005;85: 234-53

Xu JC, Ai XH and Deng XQ. Exploring the spatial and temporal dynamics of land use in Xizhuang watershed of Yunnan, southwest China. International Journal of Applied Earth Observation and Geoinformation 2005;7:299-309 